\title{
CONTRIBUTIONS TO THE MARINE PROPELLERS HYDRODYNAMIC DESIGN
}

\author{
B. I. Favacho, IBSTRACT \\ J. R. P. Vaz, \\ and A. L. A. Mesquita \\ The navigation in Amazon region is very important due to the length of \\ navigable rivers and the lack of alternative road network, as well as being a \\ form of transportation costless for the flow of agricultural and \\ manufacturing production. This kind of transportation present social, \\ economic and technological importance for this region. Thus, this work \\ objective to develop a mathematical approach for the marine propellers \\ design, using a formulation for chord and pitch angle optimization, taken \\ into account the equations of mass, energy and momentum balance for the \\ theoretical calculation of thrust and torque relationships on an annular \\ control volume, ie, the mathematical model is based in the Blade Element \\ Momentum (BEM) theory. The proposed hydrodynamic model present low \\ computational cost and it is easy to implement. The results are compared \\ with classical Glauert's theory and the experimental data of the Wageningen \\ B3-50 propeller, presenting good agreement.
}

Received: October 29, 2014 Revised: November 30, 2014 Accepted: December 30, 2014

Keywords: marine propellers, glauert's theory, wageningen b3-50 propeller

\section{NOMENCLATURE}

a axial interference factor

A swept area of the propeller

$a^{\prime}, \quad$ tangential interference factor

$c \quad$ length of the chord, $m$

$C_{\mathrm{D}} \quad$ drag coefficient

$C_{\mathrm{L}} \quad$ lift coefficient

$D \quad$ diameter of the propeller, $\mathrm{m}$

$J \quad$ advance coefficient

$K_{\mathrm{T}} \quad$ thrust coefficient

$K_{\mathrm{Q}} \quad$ torque coefficient

$n$ rotational speed, RPS

$N \quad$ number of blade

$P \quad$ pitch, $\mathrm{m}$

Q torque, $\mathrm{Nm}$

$r$ radial position, $\mathrm{m}$

$\mathrm{R} \quad$ radius of the propeller, $\mathrm{m}$

$s \quad$ propeller solidity

$\mathrm{T}$ thrust, $\mathrm{N}$

$V$ freestream velocity, $\mathrm{m} / \mathrm{s}$

$x \quad$ local-speed ratio

$W \quad$ relative velocity, $\mathrm{m} / \mathrm{s}$

\section{Greek symbols}

$\alpha \quad$ angle of attack, rad

$\varepsilon \quad$ viscous effect

$\eta \quad$ efficiency of the propeller

$\Omega \quad$ angular speed, $\mathrm{rad} / \mathrm{s}$

$\Phi \quad$ effective pitch angle, rad

$\rho$ density, $\mathrm{kg} / \mathrm{m}^{3}$

$\theta$ twist angle of the blade section, rad $\lambda$ parameter obtained from the forces acting on a blade section of the propeller, defined in Eqs. (5) and (6)

$\Gamma \quad$ function of the effective pitch angle, used in the Newton-Raphson method

\section{Subscripts}

opt means optimum parameter

0 indicate initial value for the first iteraction

1 index of the parameter $\lambda$, and indicates the normal direction

2 index of the parameter $\lambda$, and indicates the tangential direction

\section{Superscripts \\ $i \quad$ index of the iterative process}

\section{INTRODUCTION}

The Amazon river is the largest navigable river of the world, as in length and in water flow, transporting around $15 \%$ to $20 \%$ when compared with the other rivers that flow to the sea (Costa, 2004). Facing this reality, studies on the efficient marine propellers design are very important in this region. Therefore, aiming to present feasible and alternative methodologies, which may be implemented in the Amazonian context, a study on the propeller blade optimization based in the BEM theory is performed. This model, presents easy implementation, low computational time and good agreement with experimental data (Benini, 2004). 
The complexity of propeller blades design is high, since it is necessary to consider the influence of viscous flow around the propeller, as the effect of cavitation (O'Brien, 1962 and Carlton, 1994). The utilization of numerical techniques is becoming increasingly significant, presenting good practice results. In spite of theoretical techniques are more consistent in relation to the precision of the propellers design, these techniques are much more complicated to be developed by the necessity of physical knowledge of the characteristics of the flow around the propeller. Given these needs, this paper proposes to elaborate a mathematical model for hydrodynamic design of marine propellers, in order to contribute to the various types of boats found in the region, as well as presenting procedures to facilitate the implementation by producers and users. The results obtained with the proposed methodology present good agreement when compared with classical Glauert's theory (Glauert, 1935) and the experimental data of the Wageningen B3-50 propeller.

\section{MATHEMATICAL MODEL}

In order to obtain a more effective contribution, referring to actual situation of the marine propeller utilization, in this work a mathematical model for the hydrodynamic design of marine propellers is proposed, which is based in the BEM method (Glauert, 1935). BEM method is a widely used approach for the analysis and design of propellers. This approach, combining the basic principles from both blade element (Rankine, 1865 and Froude, 1878) and momentum theories, is inherently steady, two-dimensional, stems from the equivalence between the circulation and momentum theories of lift, and allows to estimate the inflow distribution along the blade. It is possible to determine the optimal geometry of a propeller using BEM. For this, it is necessary to understand that the principle of marine propellers operation is based on creating a fluid stream in the opposite direction to a vessel displacement, and whose impulse is able to overcome the forces of resistance imposed by the fluid in which the vessel moves (Gerr, 1989). So considers a propeller capable of transferring energy to the flow axis. Figure 1 shows the streamlines and the control volume for the theoretical propeller case. The velocities $V, V_{1}$ and $V_{2}$ are freestream velocities in the propeller plane and wake, respectively.

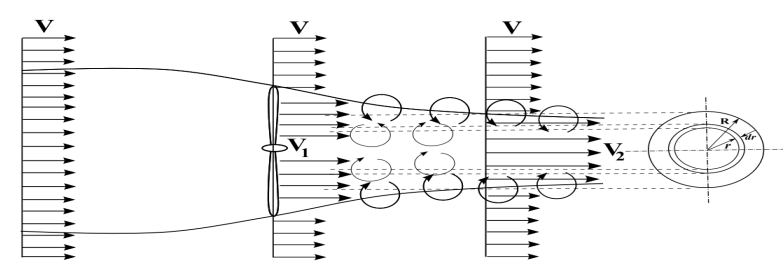

Figure 1. Control volume for an ideal propeller.
According to the classical references (Glauert, 1935, Rankine, 1865 and Froude, 1878), the efficiency of the propeller is a function of the effective pitch angle.

$$
\eta=\frac{1-a^{\prime}}{1+a} \frac{\tan \phi}{\tan (\phi+\varepsilon)}
$$

Axial and tangential interference $a$ and $a$, respectively are dependent on $\phi$ and the viscous effects and $\varepsilon \approx \operatorname{tg} \varepsilon=C_{D} / C_{L}$, where $C_{D}$ and $C_{L}$ are drag and lift coefficients, respectively.

$$
\begin{gathered}
\frac{a}{1+a}=\frac{s \lambda_{1}}{2[1-\cos (2 \phi)]} \\
\frac{a^{\prime}}{1-a^{\prime}}=\frac{s \lambda_{2}}{2 \sin (2 \phi)}
\end{gathered}
$$

where $s$ is the propeller solidity, and is defined by:

$$
s=\frac{N c}{2 \pi r}
$$

The parameters $\lambda_{1}$ and $\lambda_{2}$, shown in Eqs. (2) and (3) are obtained from the analysis of lift and drag forces acting on a section of the propeller blade, in accordance with Fig. 2, correspond to the resultant of the forces on the normal and tangential directions, normalized by the term $1 / 2 \rho A W^{2}$.

$$
\begin{aligned}
& \lambda_{1}=C_{L} \cos \phi-C_{D} \sin \phi \\
& \lambda_{2}=C_{L} \sin \phi+C_{D} \cos \phi
\end{aligned}
$$

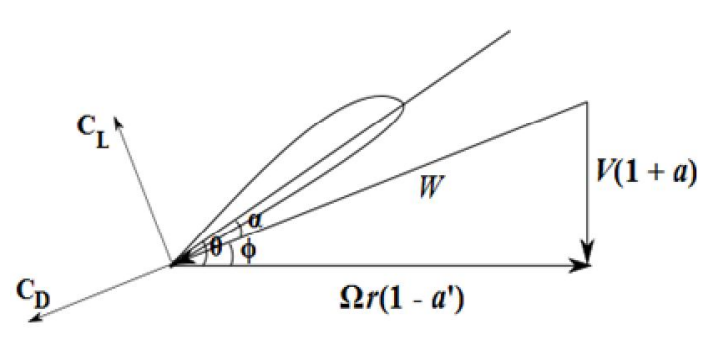

Figure 2. Velocities and forces acting on a section of the blade.

In this case $r$ is the radial position along the blade, $\Omega$ is the angular speed of the propeller, $W$ is the relative velocity on the blade section, $\alpha$ is the angle of incidence (or angle of attack), $\theta$ is the twist angle of the propeller blade section (or geometric pitch angle). The maximum efficiency is obtained by differentiating Eq. (1) in relation to the effective pitch angle $\phi$, and eliminating $a$ and $a^{\prime}$ using Eqs. (2) and (3), resulting in: 


$$
\begin{aligned}
& \Gamma(\phi)=-4 C_{D} s \cos \phi+2 C_{D} C_{L} s^{2} \cos (2 \phi) \\
& \quad+4 C_{D} s \cos (3 \phi)+4 C_{D} s \cos (2 \varepsilon+\phi) \\
& \quad-4 C_{D} s \cos (2 \varepsilon+3 \phi)-4 \sin (2 \varepsilon) \\
& -4 C_{L} s \sin \phi-8 \sin (2 \phi)-C_{D}^{2} s^{2} \sin (2 \phi) \\
& +C_{L}^{2} s^{2} \sin (2 \phi)+4 C_{L} s \sin (3 \phi)+4 \sin (4 \phi) \\
& +8 \sin [2(\varepsilon+\phi)]+C_{D}^{2} s^{2} \sin [2(\varepsilon+\phi)] \\
& +C_{L}^{2} s^{2} \sin [2(\varepsilon+\phi)]+2 C_{L} s \sin (2 \varepsilon+\phi) \\
& -4 \sin [2(\varepsilon+2 \phi)]+2 C_{L} s \sin (2 \varepsilon+3 \phi)=0
\end{aligned}
$$

The subscript opt means optimum parameter. Eq. (7) is a non-linear equation in $\phi_{\text {opt }}$, and can be solved using the Newton-Raphson method.

$$
\phi_{o p t}^{i+1}=\phi_{o p t}^{i}-\frac{\Gamma\left(\phi_{o p t}^{i}\right)}{\Gamma^{\prime}\left(\phi_{o p t}^{i}\right)}
$$

The superscript $i$ is the index of the iterative process. The geometric shape of the propeller is obtained from the calculation of the chord and geometric pitch angle distributions along the blade, which is given by:

$$
c_{o p t}=\frac{4 \pi r}{N} \frac{a_{o p t}}{1+a_{o p t}} \frac{1-\cos \left(2 \phi_{o p t}\right)}{\lambda_{1}}
$$

and

$$
\theta_{o p t}=\tan ^{-1}\left[\frac{1+a_{o p t}}{x\left(1-a_{o p t}^{\prime}\right)}\right]+\alpha
$$

where $x$ is the local-speed ratio, defined by:

$$
x=\frac{\Omega r}{V}
$$

Usually the geometric pitch angle is obtained by the intersection of a blade by coaxial right circular cylinders of different radii (O'Brien, 1962). Thus, the geometric pitch angle is classically defined by:

$$
\theta_{o p t}=\tan ^{-1}\left(\frac{P / D}{\pi r / R}\right)
$$

where $P / D$ is the pitch ratio normalized by the diameter of propeller, $D$. In the iteractive procedure, the initial value of the effective pitch angle $\phi_{0}$ is obtained from velocity diagram shown in Fig. 2, given by:

$$
\tan \phi_{0}=\frac{1+a_{0}}{x\left(1-a_{0}{ }^{\prime}\right)}
$$

The local advance coefficient of the propeller is:

$$
J=\frac{V}{n D}=\pi \frac{r}{R} \frac{V}{r \Omega}=\pi \frac{r}{R} \frac{1-a^{\prime}}{1+a} \tan \phi
$$

The overall thrust produced and torque absorbed by the propeller can be obtained by integrating the elementary components along the radius.

$$
\begin{gathered}
T=\int_{r_{\text {boss }}}^{R} d T=\int_{r_{\text {boss }}}^{R} \frac{1}{2} \rho W^{2} N c \lambda_{1} d r \\
Q=\int_{r_{\text {boss }}}^{R} d Q=\int_{r_{\text {boss }}}^{R} \frac{1}{2} \rho W^{2} N c \lambda_{2} r d r
\end{gathered}
$$

The performance coefficients are:

$$
\begin{gathered}
K_{T}=\frac{T}{\rho n^{2} D^{4}} \\
K_{Q}=\frac{Q}{\rho n^{2} D^{5}} \\
\eta=\frac{J}{2 \pi} \frac{K_{T}}{K_{Q}}
\end{gathered}
$$

The iterative procedure for the calculation of optimum chord and geometric pitch angle at each section of the propeller blade is given as follows:

\section{Algorithm}

Require: $\Omega, \mathrm{r}, \alpha, \mathrm{C}_{\mathrm{L}}(\alpha), \mathrm{C}_{\mathrm{D}}(\alpha)$ and $\mathrm{V}_{0}$.

Set initial values to $a$ e $a$ '.

For $i=1$ to $N s$ (Number of sections) do

Compute the initial value to $\phi_{0}$, using Eq. (13);

While error $>$ TOL do

$$
\text { iter }=\text { iter }+1
$$

Compute $\lambda_{1}$ and $\lambda_{2}$, using Eq. (5) and (6), respectively;

Compute $c_{\text {opt }}$, using Eq. (9);

Compute $s$ using Eq. (4);

Compute $\phi_{\text {opt }}$ using Eq. (7), which is solving by Newton-Raphson method in Eq. (8);

Compute $\theta_{o p t}$, using Eq. (12);

Compute $a_{\text {opt }}$ and $a_{\text {opt }}^{\text {, }}$, using Eq. (2) and (3), respectively.

Compute error $=\left|\phi_{o p t}^{i t e r+1}-\phi_{o p t}^{i t e r}\right|$;

\section{end While}

end For

Compute the optimum propeller blade geometry: chord and geometric pitch angle distributions. 


\section{RESULTS AND DISCUSSIONS}

\section{Results for the Proposed Hydrodynamic Model}

In order to evaluate the behavior of the proposed method, the information shown in Tab. 1 is considered. The data were obtained from the classical Glauert's theory (1935), which considering a theoretical propeller. The parameters were calculated for $r / R=0.7, s=0.1$ and $\theta=24^{\circ}$.

Table 1. Parameters for an element of blade.

\begin{tabular}{|c|c|c|c|c|c|c|}
\hline$\alpha\left(^{\circ}\right)$ & $\phi\left(^{\circ}\right)$ & $\lambda_{1}$ & $\lambda_{2}$ & $a$ & $a^{\prime}$ & $J$ \\
\hline 4 & 20 & -0.012 & 0.036 & -0.003 & 0.003 & 0.80 \\
\hline 6 & 18 & 0.204 & 0.088 & 0.056 & 0.007 & 0.67 \\
\hline 8 & 16 & 0.410 & 0.132 & 0.156 & 0.012 & 0.54 \\
\hline 10 & 14 & 0.610 & 0.164 & 0.363 & 0.017 & 0.40 \\
\hline 12 & 12 & 0.780 & 0.178 & 0.820 & 0.021 & 0.25 \\
\hline 14 & 10 & 0.964 & 0.186 & 4.000 & 0.026 & 0.08 \\
\hline 16 & 8 & 1.136 & 0.180 & -3.13 & 0.032 & -0.14 \\
\hline
\end{tabular}

Figure 3 shows a comparison between the propeller efficiency obtained with the proposed model and the results described by Glauert (1935). Note that for zero drag $(\varepsilon=0)$, ie, without the influence of viscous dissipation, the present methodology converges to the Glauert's model (1935) (see Figure 3a). As well the increase of the viscous dissipation $(\varepsilon>0)$ promotes a significant decrease at the propeller local efficiency. This effect was predicted by Glauert (1935) and other classical authors in the literature as O'Brien (1962) and Carlton (1994). In the present model, this losses is predicted through the hydrodynamic characteristics of the hydrofoil, which can be obtained from experimental survey or numerical simulation (Abbot and Doenhoff, 1959, and Drela, 1989). Thus, these results indicate that the proposed methodology present physical consistency. The value of $\varepsilon>0$ was omitted in the Glauert's work (1935). The optimal effective pitch angle is given by $\mathrm{Eq}(8)$, which is calculated using Newton-Raphson method applied on Equation (7). Figure $3 \mathrm{~b}$ shows the behavior of the optimization method, where the method always converges to the maximum efficiency for any $\varepsilon$. Table 2 presents optimal results for the proposed method.

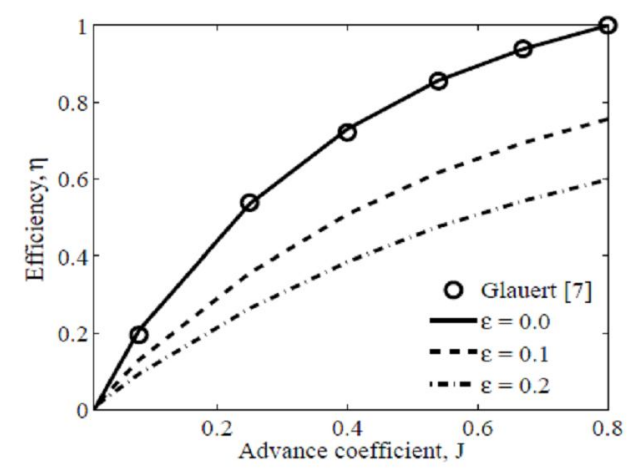

(a)

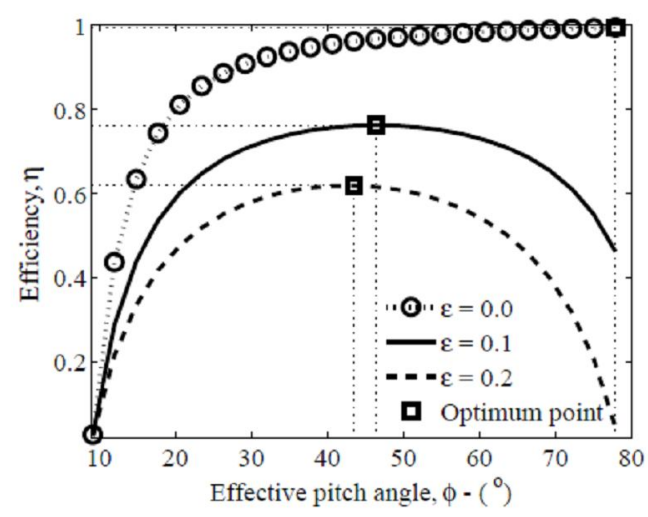

(b)

Figure 3. (a) Local efficiency as a function of the local advance coefficient. (b) Local efficiency as a function of the effective pitch angle.

Note that viscous dissipation has a strong influence on the propeller efficiency. Equation (1) shows the efficiency behavior as a function of $\varepsilon$. In other words, the efficiency decrease when the viscous dissipations increase.

Table 2. Results obtained using Eqs. (1) and (7).

\begin{tabular}{|c|c|c|}
\hline$\varepsilon=C_{\mathrm{D}} / C_{\mathrm{L}}$ & $\Phi_{p t}\left({ }^{\circ}\right)$ & $\eta_{\max }(\%)$ \\
\hline 0.0 & 78 & 100 \\
\hline 0.1 & 46 & 76 \\
\hline 0.2 & 43 & 62 \\
\hline
\end{tabular}

\section{Comparison with the B3-50 Propeller}

To evaluate the proposed optimization method, a comparison with the open-water characteristics of 3-bladed Wageningen B-series propeller (Troost, 1951 and Lammeren et al, 1969) is performed, having a blade-area ratio of 0.5 , this propeller geometry corresponding to a pitch ratio $P / D=0.6$. The Wageningen series was chosen being a well known test case in the literature (Carlton, 1994 and Glauert, 1935), the behavior of which has been deeply studied in the past, and which is currently representative of general purpose fixed-pitch propeller design. The performance of the Wageningen propellers were calculated using the polynomials provided by Oosterveld and Oossanen (1975), which are based on accurate regression analyses from experimental data on propeller models. Rotational speed was fixed at $331 \mathrm{rpm}$, while the undisturbed flow velocity $V$ was varied in order to obtain different values of the advance coefficient $J$. The blades geometries are shown in Tab. 3. For the proposed model was considered the same operation conditions of the Wageningen B3-50. Figure 4 reports the comparison between experimental and proposed model, which present a good physical consistency. 
Table 3. Blade geometries of the propellers.

\begin{tabular}{|c|c|c|c|c|c|}
\hline$N s$ & $r / R$ & $c / R$ & $\theta-(\mathrm{rad})$ & $c^{* / R}$ & $\theta^{*}-(\mathrm{rad})$ \\
\hline 1 & 0.2 & 0.272 & 0.762 & 0.602 & 0.762 \\
\hline 2 & 0.3 & 0.305 & 0.567 & 0.945 & 0.567 \\
\hline 3 & 0.4 & 0.333 & 0.445 & 1.225 & 0.445 \\
\hline 4 & 0.5 & 0.353 & 0.365 & 1.335 & 0.365 \\
\hline 5 & 0.6 & 0.364 & 0.308 & 1.227 & 0.308 \\
\hline 6 & 0.7 & 0.361 & 0.264 & 0.951 & 0.266 \\
\hline 7 & 0.8 & 0.354 & 0.223 & 0.627 & 0.234 \\
\hline 8 & 0.9 & 0.276 & 0.186 & 0.356 & 0.209 \\
\hline 9 & 1.0 & 0.000 & 0.155 & 0.177 & 0.189 \\
\hline
\end{tabular}

(*) Correspond to results obtained with proposed model.

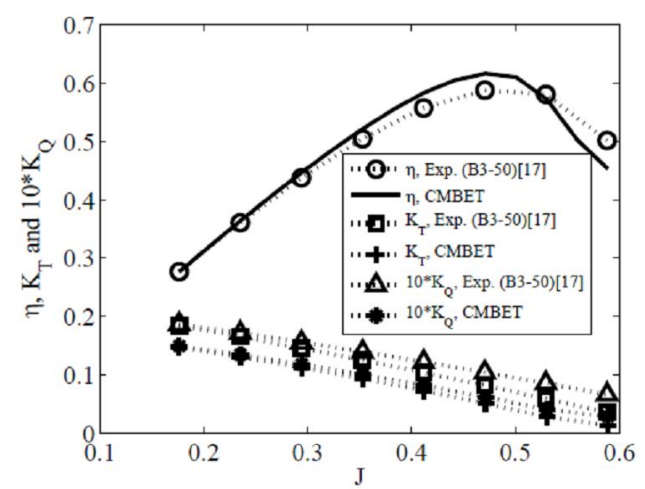

Figure 4. Propeller efficiency, thrust and torque coefficients as functions of advance coefficient.

\section{Results for the Optimization Model}

In this case the simulation is considered in "open water". For performance analysis of the propeller a simple but effective BEM method is used, which was described in the early work by Glauert (1935) Rankine (1865) and Froude (1878). As it is well known, in this method the propeller blade is divided into a number of elementary streamtubes (called "strips") along the radius, where a force balance is applied involving two-dimensional profile lift and drag along with the thrust and torque produced within the strip (Wald, 2006). At the same time, a balance of axial and angular momentum is applied. According Benini (2004), the BEM present good agreement with experimental data. To show the behavior of the proposed optimization method, an application of the performance prediction of 3-bladed propeller is carried out. In this case the simulation is performed for a propeller with diameter of $0.6 \mathrm{~m}$, having 3 different values of the pitch ratio $(P / D=1.0$, 1.5 and 2.0). Rotational speed was fixed at $400 \mathrm{rpm}$, while the undisturbed velocity $V$, and the advance coefficient $J$ were varied. The propeller blade geometry is presented in Tab. 4. Figure 5 shows the blade geometry and the propeller designed for $P / D=$ 1.5 .
Table 4. Blade geometries of the propeller.

\begin{tabular}{|c|c|c|c|c|c|}
\hline$N s$ & $r / R$ & $c / R$ & $\theta^{*}-(\mathrm{rad})$ & $\theta^{* *}-(\mathrm{rad})$ & $\theta^{* * *}-(\mathrm{rad})$ \\
\hline 1 & 0.199 & 0.446 & 1.009 & 1.174 & 1.266 \\
\hline 2 & 0.288 & 0.616 & 0.833 & 1.026 & 1.144 \\
\hline 3 & 0.377 & 0.833 & 0.700 & 0.901 & 1.035 \\
\hline 4 & 0.466 & 1.077 & 0.598 & 0.796 & 0.938 \\
\hline 5 & 0.555 & 1.318 & 0.520 & 0.709 & 0.853 \\
\hline 6 & 0.644 & 1.513 & 0.458 & 0.637 & 0.779 \\
\hline 7 & 0.733 & 1.620 & 0.409 & 0.577 & 0.714 \\
\hline 8 & 0.822 & 1.610 & 0.369 & 0.526 & 0.658 \\
\hline 9 & 0.911 & 1.476 & 0.336 & 0.482 & 0.609 \\
\hline 10 & 1.000 & 1.244 & 0.308 & 0.445 & 0.566 \\
\hline
\end{tabular}

$(*)$ Correspond to $\mathrm{P} / \mathrm{D}=1.0,(* *)$ to $\mathrm{P} / \mathrm{D}=1.5$ and $(* *)$ to $\mathrm{P} / \mathrm{D}=$ 2.0.

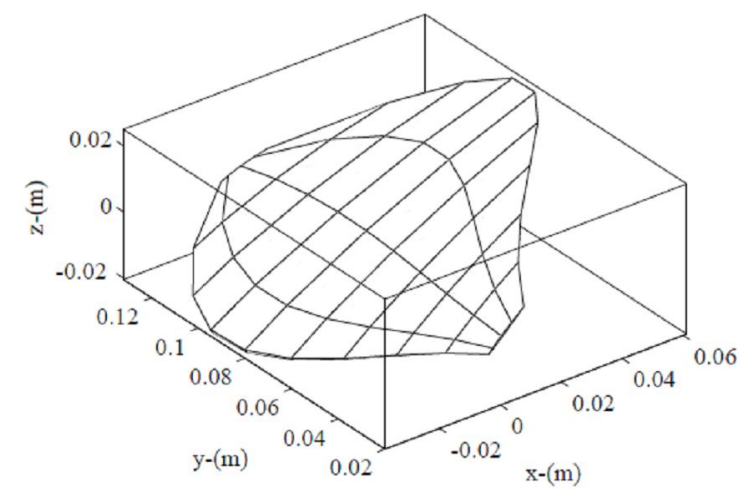

Figure 5. Propeller geometry obtained using the proposed model.

Also is used the NACA 66206 hydrofoil (Abbot and Doenhoff, 1959), which has good efficiency according to Gokarn (2004). For this hydrofoil, the Reynolds number is 2,000,000. The lift and drag coefficients was obtained using XFOIL, which correspond a coupled panel/viscous code developed at MIT (Drela, 1989). XFOIL is a collection of programs for airfoil design and analysis for incompressible/compressible viscous flows over an arbitrary airfoil. In this code, a zonal approach is used to solve the viscous flow indirectly and an equivalent inviscid flow is postulated outside a displacement streamline that includes the viscous layer, becoming a powerfull software for aerodynamic design, and present good agreement when compared with experimental data (Benini, 2004). Figure 6 shows the lift and drag coefficients, respectively, generated using 120 panels.

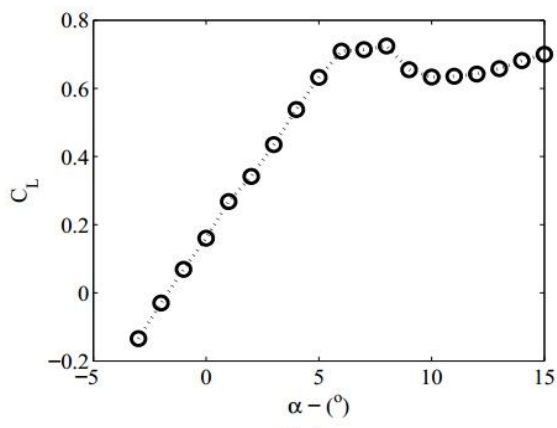

(a) 


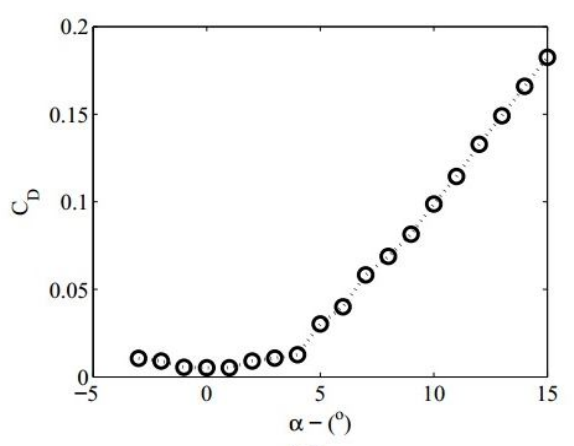

(b)

Figure 6. (a) Lift coefficient. (b) Drag coefficient.

Figure 7 shows the results for $P / D=1.0$ and 1.5. The maximum efficiencies obtained are $64 \%$ and $70 \%$, respectively. This results agrees with experimental data available in the literature, eg, Benini (2004) shows results using 3-bladed Wageningen B-series screws, where the propeller efficiency is around $70 \%$ in the rated operation. The behavior of the thrust and torque coefficients is consistent with the open water characteristics of a propeller, which is usually given in terms of the advance coefficient $J$, as described in Gokarn (2004). Thus, present approach correspond to an alternative methodology for the marine propeller design, contributing to the development of ship propeller technology in the Amazon region.

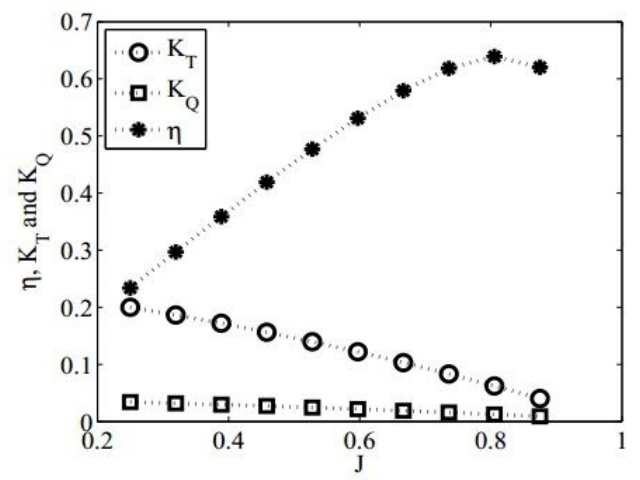

(a)

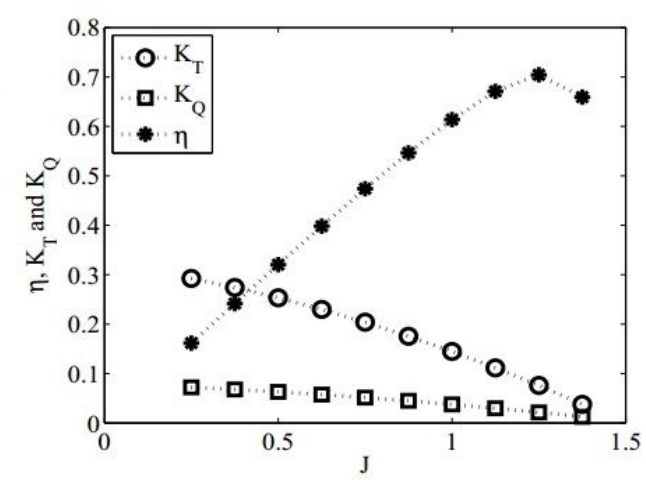

(b)

Figure 7. (a) Results for $\mathrm{P} / \mathrm{D}=1.0$. (b) Results for $\mathrm{P} / \mathrm{D}=1.5$.

\section{CONCLUSIONS}

The marine propellers design in the region is generally empirical. There are no manuscripts or references notes, instruments or equipment that can be used with some accuracy. Knowing the difficulties faced by user in conducting this type of activity, it was important to characterize the design techniques, the mapping of empiricism practiced and, especially, the development of knowledge and expertise on the hydrodynamic design of marine propellers technology, as proposition for the total or partial replacement of empiricism practiced in the region. The study is original and certainly provide promising results and technological development to current methods for the propeller design. Thus, the methodology presented in this work is an alternative approach, which is an extension of the Glauert's model (1935), considering the wake effects and the viscous influence on the propeller blades section. The proposed method presents easy implementation and low computational processing time. The results show that the mathematical model, converges to the classical Glauert's model (1935), presenting physical consistency, as well as good agreement when compared with Wageningen B3-50 propeller. The propeller designed with the methodology described in this paper has good efficiency. It is emphasized that the hydrodynamic optimization models of propeller blades are few, highlighting the difficulties in developing more accurate comparisons, especially for small vessels, which are present in greater numbers in the Amazon region. However, there are some limitations of the proposed methodology, which need to be investigated, as: (1) comparisons with experimental data for a detailed analysis of the proposed model behavior, (b) taken into account of the cavitation effect on the propeller, since, the high shaft rotations, can lead the decrease in the pressure condition on the propeller blade.

\section{ACKNOWLEDGEMENTS}

The authors would like to thank the UFPA, CNPq, CAPES and FNDE (through the agreement 16175 ) for financially supporting.

\section{REFERENCES}

Abbot, J. H., and Doenhoff, V., 1959, Theory of Wing Suctions, 2ed. Dover Publications Inc.

Costa, L. S. S., 2004, As Hidrovias nos Interiores do Brasil, Fenavega Editions, Rio de Janeiro, Brasil. (in Portuguese)

Loureiro, J. C. S., Oliveira, M. F. S., and Pinto, R. O., 2000, Ciência do Processo de Fabricação no Desempenho de Propulsores Navais Tipo Hélice Fabricados na Área Metropolitana de Belém-PA, in: Anais do $14^{\circ}$ Congresso Brasileiro de Engenharia e Ciência dos Materiais, pp. 43301- 


\section{3, São Pedro. (in Portuguese)}

Barros, A. S., Aviz, J. A. S., and Freitas, E. S., 2012, Processo de Fabricação, Estruturas de Solidificação, Propriedades Mecânicas e Desempenho Operacional de Hélices Navais Produzidos Artesanalmente no Estado do Pará, in: Anais do $20^{\circ}$ Congresso Brasileiro de Engenharia e Ciência dos Materiais, pp. 6156-6163. (in Portuguese)

Benini, E, 2004, Significance of Blade Element Theory in Performance Prediction of Marine Propellers, Ocean Engineering, Vol. 31, pp. 957-974.

O'Brien, T. P., 1962, The Design of Marine Screw Propellers, 1ed., Hutchinson \& Co (Publishers) LTD.

Carlton, J. S., 1994, Marine Propellers and Propulsion, Butterworth-Heinemann Ltd.

Glauert, H., 1935, Aerodynamic Theory, v. 6, Div. L, W. F. Durand, ed., Julius Springer, Berlin, $324 \mathrm{p}$.

Rankine, W. J. M., 1865, On the Mechanical Principles of the Action of Propellers, In: Transactions, Institute of Naval Architects, Vol. 6, pp. 13.

Froude, W., 1878, On the Elementary Relation between Pitch, Slip and Propulsive Efficiency, In: Transactions, Institute of Naval Architects, Vol. 19, pp. 47-57.

Gerr, D., 1989, Propeller Handbook, 1ed., International Marine/Ragged Mountain Press.

Drela, M., 1989, XFOIL: an Analysis and Design System for Low Reynolds Number Airfoils. in: Conference on Low Reynolds Number Airfoil Aerodynamics, University of Notre Dame.

Troost, L., 1951, Open-Water Test Series with Modern Propeller Forms, Transactions NECIES 67.

Lammeren, W. P. A., van Manen, J. D., and Oosterveld, M. W. C., 1969, The Wageningen Bscrew series, SNAME Transactions 77.

Oosterveld, M. W. C., and van Oossanen, P., 1975, Further Computer-analyzed Data of the Wageningen B-screw Series, International Shipbuilding Progress, Vol. 22, pp. 251-262.

Wald, Q. R., 2006, The Aerodynamics of Propellers, Progress in Aerospace Sciences, Vol. 42, pp. 85-128.

Gokarn, G., 2004, Basic Ship Propulsion, Allied Publishers Pvt. Limited. 